\title{
Del análisis de las relaciones entre el Estado y la Iglesia católica, al estudio conceptual y lingüístico de la secularización en los siglos XIX y XX en Colombia: una revisión historiográfica y una propuesta*
}

\section{Resumen}

Pensando en la necesidad de nuevos planteamientos para la historia de lo católico y lo religioso, se ha querido partir de cierta bibliografía al respecto para construir una propuesta novedosa. La revisión de balances bibliográficos, la definición de unos momentos de ruptura recientes en el caso colombiano, y el intento de síntesis de alguna bibliografía teórica, sumado a un breve acercamiento a la historiografía latinoamericana, han servido para el levantamiento de los hallazgos que fundan este artículo. Se propone, entonces, que debe superarse la observación de las relaciones Iglesia-Estado, y la historia interna de la institución eclesiástica en sí misma, para abordar el problema de la secularización, en una lógica que permita miradas más globales. Los aportes de la nueva historia político-intelectual, que aúnan los esfuerzos de diversas tradiciones historiográficas, permiten un acercamiento contextual distinto al problema de lo religioso católico y su transformación durante los siglos XIX y XX.

Palabras clave

Tesauro: relación Iglesia-Estado, Iglesia católica, religión, lenguajes políticos.

Autor: secularización, historia intelectual.

Referencia para citar este artículo: Largo Vargas, Joan Manuel. "Del análisis de las relaciones entre el Estado y la Iglesia católica, al estudio conceptual y lingüístico de la secularización en los siglos XIX y XX en Colombia: una revisión historiográfica y una propuesta". Anuario de Historia Regional y de las Fronteras 23.2 (2018): 25-50.

Fecha de recepción: 28/11/17

Fecha de aceptación: 19/06/2018

Joan Manuel Largo Vargas: doctorante en Historia de la Universidad Nacional de Colombia, Colombia. Magíster en Historia de la Universidad Nacional de Colombia-sede Medellín, 2017, Colombia. Historiador de la Universidad del Valle, 2013, Colombia. Miembro del Grupo de Estudios de Literatura y Cultura Intelectual Latinoamericana (GELCIL). Profesor de la Facultad de Ciencias Humanas y Económicas, Universidad Nacional de Colombia-sede Medellín, Colombia. Código ORCID: https://orcid.org/0000-0001-5937-9586. Correo electrónico: jmlargov@unal.edu.co.

\footnotetext{
* Este artículo se desprende del proyecto de tesis doctoral "El momento del orden. Pueblo, democracia y secularización en Colombia, 1886-1962”, dirigido por el doctor Juan Guillermo Gómez García. Agradezco especialmente a la profesora Diana Luz Ceballos Gómez, a cuya asesoría previa debo varios hallazgos y reflexiones.
} 


\title{
The Analysis of Relations Between Catholic Church and the State Toward Conceptual and Linguistic Study of Secularization in the 19th and 20th Centuries in Colombia: a Historiographic Review and a Proposal
}

\begin{abstract}
When thinking about the need for new approaches in the history of the Catholic faith and religion, we wanted to start from a particular bibliography in order to build a novel proposal. When reviewing some bibliographic balances, the definition of some moments of recent rupture in the Colombian case, and an attempt of synthesis of some theoretical bibliography, added to a brief approach to the Latin American historiography, were crucial to gather the findings that provide the arguments for this article. It is proposed, then, that the observation of ChurchState relations and the internal history of the ecclesiastical institution itself must be overcome in order to address the secularization problem, in a logic that allows for more global views. The contributions of the new political-intellectual history, which combine the efforts of diverse historiographical traditions, allow for a different contextual approach to the problem of the Catholic religious and its transformation during the 19th and 20th centuries.
\end{abstract}

Keywords

Thesaurus: Church-State Relations, Catholic Church, Religion, Politic Languages.

Author's keywords: Secularization, Intellectual History.

\section{A observação das relações entre a Igreja Católica e o Estado até ao estudo conceitual e linguístico da secularização no séculos XIX e XX na Colômbia: uma revisão historiográfica e uma proposta}

Resumo

Pensando na necessidade de novas abordagens da história católica e religiosa, queríamos começar de uma certa bibliografia para construir uma nova proposta. A revisão dos balances bibliográficos, a definição de alguns momentos de ruptura recente no caso colombiano e a tentativa de sintese de alguma bibliografia teórica, somada a uma breve abordagem da historiografia latino-americana, serviram para a compilação dos resultados que fundamentam este artigo. Então, é proposto que, a observação das relações IgrejaEstado e a história interna da própria instituição eclesiástica devem ser superadas para abordar o problema da secularização, numa lógica que permita visões mais globais. As contribuições da nova história político-intelectual, que combinam os esforços de diversas tradições historiográficas, permitem uma abordagem contextual diferente ao problema dos religiosos católicos e sua transformação nos séculos XIX e XX.

Palavras-chave

Thesaurus: relações igreja-Estado, igreja católica, religião, linguagens políticas.

Palavras-chave do autor: secularização, história intelectual. 


\section{Introducción}

Las tres últimas décadas del siglo XX han representado, para las ciencias sociales en general, un momento de renovación y de ruptura. Para la historiografía, particularmente, es evidente una creciente transformación en la selección de los temas y de los problemas, así como de las estrategias metodológicas y de los diálogos teóricos con otras disciplinas. Desde el estudio de las estructuras sociales y los fenómenos seriales, se ha realizado un desplazamiento hacia nuevos actores y hacia procesos de índole menos económica o sociológica, tales como las "mentalidades colectivas". ${ }^{1}$ Así mismo la "vuelta del sujeto" ha impulsado la elección de unas temáticas más acordes con lo denominado como cultural, cuyo tratamiento implicaría cada vez menos el uso de las miradas estructurales y las herramientas cuantitativas de las ciencias sociales. Si bien hasta la década de 1970 más o menos, eran la Economía y la Sociología las disciplinas que más dialogaban con la historiografía, en adelante serán la crítica literaria y la antropología las que aporten herramientas de análisis a los historiadores de las nuevas generaciones. ${ }^{2}$ El contexto político de esta transición es fundamental; por un lado, la radicalización de las izquierdas empezó a ceder con el desmoronamiento de la URSS, por el otro, el cuestionamiento a las ideas del progreso y de la modernidad, antes casi incuestionables, cimentó nuevas posturas frente al quehacer del historiador. ${ }^{3}$ Así las cosas, la disciplina histórica del último cuarto del siglo XX ha tomado distancia de la de sus predecesores. ${ }^{4}$

Una de las especificidades de América Latina en este proceso de cambio disciplinar puede notarse, especialmente, aunque no con exclusividad, en lo que ha venido a denominarse la "nueva" historia política. ${ }^{5}$ La apertura política de la década de 1980 en el cono sur, las discusiones sobre civilidad y ciudadanía en otros espacios han influido entonces de manera peculiar en el rescate de vetas de análisis antes casi ignoradas, así como en la posibilidad de un diálogo fructífero con tradiciones europeas de estudios culturales: los legados historiográficos británicos, franceses y alemanes. ${ }^{6}$ Consideramos que esta nueva historia política, en tanto que ha permitido

\footnotetext{
${ }^{1}$ Francois Dosse, La historia en migajas: de Annales a la "nueva historia" (México: Universidad Iberoamericana, 2006). De un modo paradójico esta ruptura toma forma en los trabajos de Michel Foucault, por ejemplo: Michel Foucault, La arqueología del saber (México: Siglo XXI, 2001).

${ }^{2}$ Jaume Aurell, "La transición de los setentas: de las economías a las mentalidades", La escritura de la memoria: de los positivismos a los posmodernismos (Valencia: Universitat de Valencia, 2005) 87-112.

${ }^{3}$ Sobre la experiencia puntual del Marxismo Británico y la Microhistoria italiana: Joan Manuel Largo, "Los espacios para la acción. Intersticios y tramas en la construcción del relato en la Microhistoria y el Marxismo Británico", Anuario de Historia Regional y de las Fronteras 22.2 (2017): 143-163.

${ }^{4}$ En el caso particular colombiano: Renán Silva, Lugar de dudas. Sobre la práctica del análisis histórico: breviario de inseguridades (Bogotá: Universidad de los Andes, 2014).

${ }^{5}$ Guillermo Palacios, Ensayos sobre la nueva historia política de América Latina, siglo XIX (México: El Colegio de México, 2007).

${ }^{6}$ Marcello Carmagnani, "Campos, Prácticas y Adquisiciones de la historia política latinoamericana", Ensayos sobre la nueva historia política de América Latina, siglo XIX, ed. Guillermo Palacios (México: El Colegio de México, 2007) 31-43. Carlos Malamud, “¿Cuán nueva es la nueva historia política latinoamericana?", Ensayos sobre la nueva historia política de América Latina, siglo XIX, ed. Guillermo Palacios (México: El Colegio de México, 2007), 19-30. También: Mauricio Tenorio, "Historia, cultura y
} 
una aproximación crítica a perspectivas de análisis clásicas y ha abierto caminos para temas antes esquivos o incómodos, constituye una interesante vía de acceso para el análisis de la secularización, en el contexto de los siglos XIX y XX en América Latina. Uno de los aspectos positivos de esta corriente es que ha permitido que los historiadores puedan cortar con los legados "liberales" y "nacionalistas", 7 que caracterizaban las explicaciones de los procesos de los siglos XIX y XX.

En esa lógica, uno de los objetivos de este texto es presentar un barrido bibliográfico inicial, parcial por supuesto, en torno al tratamiento de la historiografía colombiana sobre la Iglesia católica en los siglos XIX y XX, especialmente con lo que atañe a su dimensión política y sus relaciones con el Estado. Se busca, así mismo, intentar identificar algunos elementos relevantes sobre este mismo fenómeno en otros espacios de América Latina, principalmente con aquellos que ofrecen una mirada compleja de los procesos de secularización o laicización. Finalmente, y como resultado de los dos puntos enunciados, buscamos sugerir las pautas básicas para una propuesta metodológica que nos guíe en el análisis de la participación de la Iglesia católica en el mundo político colombiano de las últimas décadas del siglo XIX y de la primera mitad del siglo XX. Es importante, de entrada, señalar que nuestro propósito no es presentar un balance definitivo y profundo de una historiografía que ya se presenta con un acumulado considerable en el caso nacional, así mismo, no buscamos un enfoque que propenda por una historia interna o integral de la Iglesia católica colombiana como institución; lo que buscamos es una primera aproximación bibliográfica, que nos permita perfilar rastrear y comprender los debates en torno a la relación entre Estado y religión católica, apenas como una expresión de la construcción de un régimen liberal democrático, y los procesos de secularización. Es decir, se trata de un primer paso para una historia de los lenguajes políticos y los conceptos fundamentales en torno a la secularización.

\section{La historiografía colombiana sobre Iglesia y religión católica}

Gilberto Loaiza sostiene que para Colombia: "La primera estructura temporal de larga duración es, ni más ni menos, la tradición religiosa católica. Desde la llegada de los españoles, a fines del siglo XV, esa tradición ha sido un grueso manto que cubre nuestras sociedades que, de modo esporádico y tenue, ha sido sacudido por tentativas secularizadoras". ${ }^{8}$ Así las cosas, sería entonces posible creer que esta área de estudio constituye un campo fundamental de la reflexión historiográfica colombiana. Esto último, sin embargo, solo ha venido a constatarse en las tres últimas décadas, cuando

\footnotetext{
'América Latina'. Las dos últimas décadas del siglo XX", Historia General de América Latina, Volumen IX, Teoría y Metodología de la Historia de América Latina (París: Ediciones Unesco-Editorial Trotta, 2006) 239-266.

${ }^{7}$ Nos parece interesante señalar al respecto el trabajo de Peter Laslett, su cuestionamiento temprano a la mirada liberal de la historiografía marxista, así como el trabajo del profesor Elías José Palti.

${ }^{8}$ Gilberto Loaiza, Poder letrado. Ensayos sobre historia intelectual de Colombia, Siglos XIX y XX (Cali: Universidad del Valle, 2014) 17.
} 
se ha consolidado una tradición de análisis crítico de la historia de la religión y de la Iglesia católica. Antes de la década de 1990, se contaba con una dispersión de estudios, tanto por la diversidad de sus ejecutores como por la variada y desigual disponibilidad de los textos en bibliotecas y unidades documentales. ${ }^{9}$ Por su parte, José David Cortés muestra, en un balance sobre el tema, que pese a la profusa bibliografía producida por sectores del clero católico, así como de laicos, va a ser solo hasta finales de la década de $1980,{ }^{10}$ que se deje de pensar en la Iglesia como un simple componente de otros temas y se observe como el centro de las investigaciones. ${ }^{11}$ Este balance fue uno de los primeros en los que se realizó un barrido sobre las investigaciones de la historia del catolicismo en Colombia; su autor reconocía como una necesidad apremiante una historia global del catolicismo, una que fuera más allá de la institución para abordar rasgos estructurales. ${ }^{12}$ Propondremos en este texto que pueden identificarse al menos tres momentos en el estudio de la Iglesia católica y la religión en Colombia; a finales de la década de 1990 aparece un trabajo histórico, todavía canónico, con un tratamiento amplio del tema; en los primeros cinco años del 2000 se publican tres trabajos colectivos en torno a lo católico: Historia del cristianismo; Globalización y diversidad religiosa, y Ganarse el cielo defendiendo la religión. Finalmente, y desde cierto auge que tuvieron los estudios sobre el siglo XIX tras los "bicentenarios", podemos trazar una línea de trabajos muy bien documentados desde el 2010 hasta el 2016 .

Si a mediados de la década de 1990 ya se contaba con un número considerable de autores y publicaciones dedicados al tema de la Iglesia y el fenómeno religioso, entre 1995 y el año 2000 puede darse cuenta de un crecimiento exponencial de los mismos. Esto puede colegirse de la lectura del exhaustivo y juicioso balance que realizó el grupo de investigación Religión, Cultura y Sociedad, en la ciudad de Medellín. ${ }^{13}$ Variadas tesis de pregrado y posgrado, ponencias y textos inéditos, artículos, libros y capítulos de libros, dan cuenta de lo que se ha avanzado en el fortalecimiento de la investigación histórica y social en torno a la Iglesia y la religión en Colombia. La aparición de este grupo, además, da cuenta de las transformaciones institucionales que servirán de plataforma a algunas investigaciones de este carácter en el ámbito regional. ${ }^{14}$

\footnotetext{
9 José David Cortés, "Balance bibliográfico sobre la historia de la Iglesia católica en Colombia, 1945 1995”, Historia Crítica 12 (1996): 17.

${ }^{10}$ Un lugar especial ocupa la temprana obra de Cristopher Abel, quien no solo mostró detalladamente la influencia de las orientaciones católicas en la vida política del país, sino que además mostró el carácter heteróclito del clero, adelantándose así a trabajos recientes, en los que todavía puede observarse, en ocasiones, la tentativa de presentar el catolicismo como un bloque homogéneo y poco dinámico. Christopher Abel, Política, Iglesia y Partidos en Colombia: 1886-1953 (Bogotá: Faes-Universidad Nacional de Colombia, 1987).

${ }^{11}$ Cortés, "Balance bibliográfico" 24 y 25.

${ }^{12}$ Cortés, "Balance bibliográfico" 26.

${ }^{13}$ Grupo de investigación Religión, Cultura y Sociedad, Historiografía sobre religión, cultura y sociedad en Colombia producida entre 1995 y el 2000. Cuaderno de trabajo No. 1 (Medellín: Todográficas, 2001).

${ }^{14}$ Llama la atención que sea en Medellín donde aparezcan trabajos pioneros en torno al tema de la Iglesia católica, por ejemplo: Gloria Mercedes Arango, Sociabilidades católicas, de la tradición a la modernidad, Antioquia 1870-1930 (Medellín: La carreta, 2004); Luis Javier Ortiz, Fusiles y plegarias. Guerra de guerrillas en Cundinamarca, Boyacá y Santander (Medellín: Universidad Nacional de Colombia, 2004);
} 
Del análisis de las relaciones entre el Estado y la Iglesia católica, al estudio conceptual...

En ese mismo período, un libro paradigmático daría cuenta, parcialmente, de la necesaria sistematización que pedía Cortés en 1996, como ya hemos visto. El libro de Fernán González ${ }^{15}$ puede ser leído como una mirada de largo aliento a la Iglesia católica y su dimensión política; su mirada incluye reflexiones que van desde el período de la Conquista hasta las últimas décadas del siglo XX. Sin embargo, el carácter esquivo de las fuentes documentales empleadas por el autor, y el poco balance entre los capítulos (unos muy agudos y otros apenas descriptivos de acontecimientos) aparecen como un obstáculo, entendible si recordamos que fue una de las primeras publicaciones académicas destinadas a revisar la trayectoria de la Iglesia católica en la larga duración. González analizaba el carácter problemático del poder eclesiástico durante el llamado "periodo colonial", dando cuenta del poder que implicaba para la institución eclesiástica su influencia en el panorama educativo de los siglos XVII y XVIII, y mostraba, al mismo tiempo, la complejidad que implicó establecer un equilibrio jurisdiccional. Llama la atención, así mismo, el intento de establecer una periodización para el siglo XIX y el llamado de atención constante a observar la influencia del contexto internacional. ${ }^{16}$ El libro de González, reseñado y de amplio reconocimiento en otros balances, ${ }^{17}$ constituye un primer hito en lo que respecta a la historia de las relaciones entre Iglesia Católica y Estado, y aun representa un referente interesante para aproximarse a la historia de la Iglesia católica en la Colombia de los siglos XIX y XX. ${ }^{18}$

En el 2004 podemos ubicar otro punto significativo en lo que obedece a la historiografía de la Iglesia católica, ${ }^{19}$ o más ampliamente al fenómeno religioso cristiano; exceptuando la aparición previa de algunas publicaciones, ${ }^{20}$ Historia del cristianismo ofrecía un panorama global, al estilo del de Fernán González, aunque esta vez en una compilación dirigida por Ana María Bidegaín, y que reunía a diversos autores. En la introducción puede observarse el espíritu de síntesis que animaba este

Luis Javier Ortiz, Obispos, clérigos y fieles en pie de guerra. Antioquia 1870-1880 (Medellín: Universidad Nacional de Colombia, 2010); Patricia Londoño, Religión, cultura y sociedad en Colombia. Medellín y Antioquia, 1850-1930 (Bogotá: Fondo de Cultura Económica, 2004). Una mención especial merece el trabajo de Diana Luz Ceballos que enfrentó, desde trabajos tempranos, un análisis estructural del mundo católico, y en una perspectiva quien superaba los casos regionales: Diana Luz Ceballos Gómez, Hechicería, brujería e inquisición en el Nuevo Reino de Granada. Un duelo de Imaginarios (Bogotá: Universidad Nacional de Colombia, 1994).

${ }^{15}$ Fernán González, Poderes enfrentados. Iglesia y Estado en Colombia (Bogotá: Cinep, 1997).

${ }^{16}$ González 27, 124, 140 y 169.

${ }^{17}$ Ricardo Arias, "La historiografía de la Iglesia católica en Colombia", Balance y desafio de la Historia de Colombia al inicio del siglo XXI. Homenaje a Jaime Jaramillo Uribe, comps. Adriana Maya y Diana Bonnet (Bogotá: Universidad de los Andes, 2003) 235-263.

${ }^{18}$ Otro trabajo donde pueden encontrarse varios apuntes sobre la problemática vida política de la Iglesia en Colombia es Fernán González, Para leer la política. Ensayos de historia colombiana. 2 tomos (Bogotá: Cinep, 1997).

${ }^{19}$ Ana María Bidegain, Historia del Cristianismo en Colombia. Corrientes y diversidad (Bogotá: Taurus, 2004).

${ }^{20}$ Por ejemplo, José David Cortés, Curas y politicos: mentalidad religiosa e intransigencia en la diócesis de Tunja, 1881-1918 (Bogotá: Ministerio de Cultura, 1998); Michael Larosa, De la derecha a la izquierda. La Iglesia católica contemporánea (Bogotá: Planeta, 2000); Ricardo Arias, El episcopado colombiano. Intransigencia y laicidad 1850-2000 (Bogotá: Universidad de los Andes-Icanh, 2003). 
libro colectivo: "En el siglo XVI la Iglesia católica fue desafiada por las grandes transformaciones socioeconómicas y políticas provocadas por el surgimiento del capitalismo, que desembocaron en las reformas religiosas. En el siglo XVIII, por las revoluciones burguesas que acarrean la emancipación del sujeto; en el XIX y XX, por la sociedad industrial moderna y su creciente secularización". ${ }^{21}$ Esta obra puede considerarse como novedosa en la medida que se presenta como un avance en el estudio de las diversas corrientes religiosas del cristianismo en Colombia. La disparidad en la calidad de las entradas, y su énfasis notable en el siglo XIX constituyen sus principales problemas, pero ello no impide presentarla como un parteaguas en la historiografía de la Iglesia y la religión en Colombia. Un año más tarde, el trabajo Globalización y diversidad religiosa en Colombia ${ }^{22}$ presentará una mirada más amplia y en diálogo abierto con otros autores y referentes. Ganarse el cielo defendiendo la religión, ${ }^{23}$ también publicado en el 2005, es otra muestra de un trabajo colectivo, donde varias aproximaciones al fenómeno religioso y sus diversas facetas tomaron forma.

Lo que más llama la atención en Ganarse el cielo es su mirada a la religión católica no cómo un simple tema o componente de otros procesos, sino como un eje estructural que atraviesa la historia del país; en el preámbulo de este libro colectivo, afirma Diana Luz Ceballos que la Iglesia ha funcionado como un "factor de polarización", que contribuyó a la consolidación del proceso civilizatorio y de los conflictos al tomar un lugar destacado en el campo educativo y al propagar la visión de "los otros" como enemigos. ${ }^{24}$ Tal vez estas sean las publicaciones que, tempranamente y de un modo más acertado y amplio, han respondido a la necesidad de introducir los estudios de la religión y la Iglesia en las miradas estructurales de la historia de Colombia. En los últimos diez años, por otra parte, podemos evidenciar una dispersión de estudios sobre Iglesia y religión en Colombia, tanto en lo que atañe a las relaciones Iglesia-Estado, ${ }^{25}$ como en lo referente a los estudios sobre la religión en general.

Algunos autores, como se ha visto, han abordado la riqueza de las prácticas culturales católicas, con una mirada objetiva y como ligada a un contexto particular. Esto último, aunque evidente en varios de los balances antes citados, no ha sido lo suficientemente señalado: en las dos últimas décadas del siglo XX, la reflexión historiográfica sobre la Iglesia católica y la religión en Colombia ha acumulado las suficientes experiencias como para que hoy podamos ubicar, analizar e interrelacionar trayectorias, autores y

\footnotetext{
${ }^{21}$ Bidegain 13.

${ }^{22}$ Ana María Bidegain y Juan Diego Demera, Globalización y diversidad religiosa en Colombia (Bogotá: Universidad Nacional de Colombia, 2005). Resaltan, especialmente, las entradas de Jean Pierre Bastian y de Fortunato Mallimaci como síntoma de discusiones e intercambios con otros espacios académicos de América Latina.

${ }^{23}$ Luis Javier Ortiz y otros, Ganarse el cielo defendiendo la religión. Guerras civiles en Colombia, 18401902 (Medellín: Universidad Nacional de Colombia, 2005).

${ }^{24}$ Diana Luz Ceballos Gómez, "Preámbulo: un balance sobre problemas colombianos", Ganarse el cielo defendiendo la religión. Guerras civiles en Colombia, 1840-1902, Luis Javier Ortiz y otros. (Medellín: Universidad Nacional de Colombia, 2005) 35 y 36.

${ }^{25}$ José David Cortés, "Balance historiográfico sobre las relaciones Estado-Iglesia en Colombia desde la Independencia hasta finales del siglo XIX”, Historia y sociedad 18 (2010): 163-170.
} 
publicaciones significativas, y fundamentales como punto de partida para emprender nuevas indagaciones. Esto puede deberse a los impactos de la "diversidad religiosa" que formalizó la constitución política colombiana de 1991, como han afirmado algunos, ${ }^{26}$ y por supuesto al incremento considerable de los estudios históricos en los últimos años. ${ }^{27}$ Lo que si costaría mucho actualmente, es agrupar estos estudios en unas corrientes o perspectivas puntuales, dado que lo primero con lo que nos encontramos es con una multiplicidad de enfoques y aproximaciones, que bien pueden alimentarse de la tradición francesa y su discusión sobre el laicismo, ${ }^{28}$ de referentes investigativos anglosajones desde los estudios de la cultura, ${ }^{29} \mathrm{o}$ un sano eclecticismo en diálogo abierto con varias historiografías.

El final de la primera década del siglo XXI, y la ocasión del Bicentenario, impulsó un repunte de las investigaciones en torno a la llamada "independencia"; el lugar de la Iglesia católica en tal proceso, tema ya abordado en trabajos clásicos, fue uno de los retornos notables. ${ }^{30}$ La influencia de la iglesia en la independencia es un tema interesante porque lo que muestra es una mirada no "revanchista", capaz de valorar objetivamente el papel de la institución eclesiástica. Por otra parte, en varias revistas académicas colombianas circulan otras entradas recientes, que en su conjunto no dejan ver ni una uniformidad temática, ni temporal ni mucho menos teórica. ${ }^{31}$ No obstante, en los últimos años contamos con destacados libros, indicadores de acumulados individuales de investigadores nacionales, con los que debe dialogarse necesariamente para la elaboración de nuevos acercamientos.

\footnotetext{
${ }^{26}$ Grupo de investigación Religión, Cultura y Sociedad, Historiografia sobre religión...

${ }^{27}$ Dicho crecimiento respecta al fortalecimiento de programas de posgrado en ciudades como Medellín y Bogotá, así como el crecimiento de redes mediante revistas académicas: José Rueda, "Balance historiográfico de una nación fragmentada y en conflicto, 1999-2009”, Boletín cultural y bibliográfico 45.79-80 (2011): 193-252. Un balance bastante injusto y desigual de las transformaciones recientes de la historiografía colombiana en Silva, Lugar de dudas.

${ }^{28}$ Por ejemplo, Ana María Bidegaín, Iglesia, pueblo y política. Un estudio de conflictos de intereses: Colombia, 1930-1955 (Bogotá: Universidad Javeriana, 1985) y Arias, El episcopado.

${ }^{29}$ Londoño, Religión; Larosa, De la derecha a la izquierda.

${ }^{30}$ José David Cortés, "La lealtad al monarca español en el discurso político religioso en el Nuevo Reino de Granada", Anuario Colombiano de Historia Social y de la Cultura 37.1 (2010): 43-83; Fernando Muñoz, “Aproximación al imaginario religioso del periodo independentista”, Historia y Espacio 6.35 (2010): 177200; Viviana Arce, "El púlpito entre el temor y la esperanza: ideas de castigo divino y misericordia de Dios en la oratoria sagrada neogranadina, 1808-1820", Anuario de Historia Regional y de las Fronteras 17. 1 (2012): 77-107; Viviana Arce, "La Biblia como fuente de reflexión política en los sermones neogranadinos, 1808-1821”, Revista CS 9 (2012): 273-307.

${ }^{31}$ Citamos solo algunos que son de utilidad para nuestra perspectiva de análisis: Iván Alexander De la Ossa, "Santificados sean los próceres: historia y religiosidad en los centenarios payaneses, 1910-1916", Historia y Espacio 45 (2015): 119-145; Adriana Santos, "Civilización e instrucción pública en los territorios nacionales: consensos entre liberales radicales e Iglesia católica del Magdalena”, Historia Caribe 7.21 (2012): 27-53; Luis Javier Ortiz, "Manuel Canuto Restrepo y Villegas, 1825-1891. Un obispo en guerras civiles colombianas, entre la Comuna de París y la Comuna de Pasto", Historia y Espacio 37 (2011): 147187; Adriana Santos, "Conectarse con Dios en la frontera. Impresos católicos y sociedad: la experiencia del Magdalena durante los gobiernos liberales radicales del siglo XIX”, Historia y Espacio 37 (2011): 127-146.
} 
En primer lugar, debemos señalar el trabajo del profesor Gilberto Loaiza, ${ }^{32}$ quien ha aportado una rica revisión del siglo XIX. Según este autor encontramos una pugna en clave de la política moderna- dentro de una triangulación de sectores de la sociedad decimonónica: los liberales, los conservadores católicos, y el pueblo. ${ }^{33}$ De la propuesta de Loaiza destaca la apropiación del trabajo de Maurice Agulhon y su perspectiva de las sociabilidades, lo que, en últimas, permite observar no a un anquilosado ejército de intelectuales católicos, inmóviles y vetustos, sino a un activo sector de la sociedad poniendo sus representaciones en la disputa de la opinión pública. No obstante, el cuidadoso trabajo documental y teórico del profesor Loaiza, no es difícil percibir cierto tono pesimista y amargo frente a la derrota sucesiva de los proyectos letrados liberales. También con una afiliación depurada a la tradición sociológica francesa, contamos con el trabajo de William Beltrán. ${ }^{34}$ En este último es notable el influjo de Jean Pierre Bastian, lo que conduce a Beltrán a examinar detalladamente -en un análisis que para décadas recientes deja mucho a lo cuantitativo- el relativo desgaste de la tradición católica colombiana durante el siglo XX.

Finalmente, debemos subrayar dos últimos elementos que serán de gran utilidad para la última parte de este artículo. Primero el lugar de cierta historiografía regional de lo religioso, lo que estaría apuntando a la posibilidad de elaborar reflexiones de largo aliento sin el impedimento de un desbordado trabajo documental; monografías y libros que abordan la historia del catolicismo y de la Iglesia en varias regiones del país se presentan como un insumo para ensayar explicaciones a nivel nacional. ${ }^{35}$ En segundo lugar, los trabajos recientes de Beatriz Castro Carvajal ${ }^{36}$ y de José David Cortés, ${ }^{37}$ centrados en las relaciones Iglesia-Estado en Colombia durante los siglos XIX y XX. Mientras que la primera reflexiona sobre la creación de un "Estado social" y el papel que jugó una institución católica en ese fenómeno -la Congregación de las

\footnotetext{
${ }^{32}$ Nos referimos a una parte de la tesis doctoral en sociología de Loaiza -bajo la dirección de Jean Pierre Bastian-, cuya publicación lo hizo merecedor del premio Alejandro Ángel Escobar en el 2012: Gilberto Loaiza, Sociabilidad, religión y política en la definición de la Nación. Colombia 1820-1886 (Bogotá: Universidad Externado de Colombia, 2011).

${ }^{33}$ Nuevas aproximaciones, en esa misma clave, en Loaiza, El poder letrado... y Gilberto Loaiza, "La utopía conservadora de la nación católica”, Utopías Móviles. Nuevos caminos para la historia intelectual en América Latina, ed. Selnich Vivas (Bogotá: Diente de León-Universidad de Antioquia, 2014) 264-283.

34 William Beltrán, Del monopolio católico a la explosión pentecostal. Pluralización religiosa, secularización y cambio social en Colombia (Bogotá: Universidad Nacional de Colombia, 2013).

${ }^{35}$ William Plata, El hecho religioso: historia en perspectiva regional (Bucaramanga: Universidad Industrial de Santander, 2013). Adriana Santos, “¡Ni tan lejos ni tan cerca!: construcción de la Iglesia en tiempos del liberalismo. La experiencia del Magdalena en el Caribe colombiano (1850-1880)" (Tesis, Doctorado en Historia, Universidad Pablo de Olavide, 2015). Destaca, por otra parte, la figura de Antonio Echeverry y Carolina Abadía, Historia de la Iglesia Católica en el Valle del Cauca (Cali: Universidad del Valle, 2015); Antonio Echeverry y Carolina Abadía, Aproximación histórica a la Diócesis de Cali (Cali: Universidad del Valle, 2010). Más al sur debe señalarse también el trabajo de Amanda Caicedo, Construyendo la hegemonía religiosa. Los curas como agentes hegemónicos y mediadores socioculturales (Diócesis de Popayán, Siglo XVIII) (Bogotá: Universidad de los Andes, 2008).

${ }^{36}$ Beatriz Castro, La relación entre la Iglesia católica y el Estado Colombiano en la Asistencia social c. 1870-1960 (Cali: Universidad del Valle, 2014).

${ }^{37}$ José David Cortés, La batalla de los siglos. Estado, Iglesia y religión en Colombia en el siglo XIX. De la Independencia a la Regeneración (Bogotá: Universidad Nacional de Colombia, 2016).
} 
Hermanas Dominicas de la Presentación-; el segundo presenta una reflexión extensa sobre los elementos ideológicos y políticos de la relación Estado-Iglesia durante casi todo el siglo XIX. Estas dos últimas contribuciones nos impiden hablar de la ausencia total de un análisis intelectual de los debates sobre las relaciones Iglesia-Estado, pero al mismo tiempo nos convocan a intentar nuevas aproximaciones, dado que ni Castro ni Cortés han realizado sus investigaciones centrándose en la perspectiva de la historia intelectual, por lo que han dado grandes espacios a una reflexión a veces demasiado rica en detalles y acontecimientos, lo que se explica, desde luego, por los grandes alcances que se han propuesto en cuanto a su espacio temporal.

\section{Algunas perspectivas en América Latina sobre Iglesia católica y religión}

Ahora bien, actualmente es insoslayable buscar cercanía con otras tradiciones historiográficas, si es necesario estar al día en cuanto a la sofisticación teórica y metodológica europea, es igualmente determinante estar al tanto de las experiencias investigativas dentro del espacio latinoamericano. Para tal efecto hemos partido de una pequeña selección casi reducida a las experiencias de Ecuador, México, Chile y Argentina, en tanto que consideramos que representan los casos más llamativos. Por otra parte, es posible encontrar trabajos tempranos, locales y desde Europa, que intentan abordar a América Latina en lo que puede tener de global.

Cabe, en ese último sentido, recordar cierta afirmación de Jean Pierre Bastian, en un trabajo ya clásico:

Para liberarse del control de los liberales y de los conservadores y conservar una verdadera autonomía frente al Estado, la Iglesia latinoamericana se hizo ultramontana. Así, al volverse a Roma, novedad extraordinaria al cabo de tres siglos de patronato ibérico, la Iglesia esperaba oponer resistencia al regalismo de los gobiernos independientes. En este sentido, el siglo XIX ofreció a la Iglesia latinoamericana la ocasión de afirmar por primera vez su soberanía frente al Estado. ${ }^{38}$

El dato más interesante de esta afirmación es la necesidad de ubicar la experiencia latinoamericana frente a las transformaciones decimonónicas europeas, así como en la posibilidad de buscar ciertas equivalencias o líneas afines entre las trayectorias de los países iberoamericanos. La corriente católica ultramontana se organizaría con mayor claridad en Europa durante el pontificado de Pío IX (1846-1878); más allá de rehuir la sociedad civil, la Iglesia asumiría durante ese periodo y comienzos del siglo XX, toda una ofensiva por medio de prácticas asociativas y letradas plenamente configuradas en los lenguajes políticos modernos. En algunos países como México, Perú y Ecuador, ${ }^{39}$ debido a la importancia

\footnotetext{
38 Jean-Pierre Bastian, Protestantismos y modernidad en América Latina. Historia de unas minorías religiosas activas en América Latina (México: Fondo de Cultura Económica, 1994).

${ }^{39}$ Cecilia Bautista, Las disyuntivas del Estado y de Iglesia en la consolidación del Orden Liberal. México, 1856-1910 (México: El Colegio de México, 2012); Pilar García, Iglesia y poder en el Perú contemporáneo, 1821-1919 (Lima: Centro de Estudios Regionales Andinos, 1991).
} 
demográfica de las comunidades indígenas, puede suponerse que la Iglesia seguiría jugando un papel importante; Argentina y Venezuela, por su parte, con una fuerte tradición liberal, presentarían durante el transcurso del siglo XIX varios intentos efectivos de secularización. En países como Chile y Colombia podrían establecerse ciertos paralelos -hipótesis por demostrar-, donde tras varios intentos de reformas secularizadoras se desemboca en un siglo XX con una Iglesia católica vigorosa. ${ }^{40}$

Un estudio pionero sobre la tradición católica en el espacio andino, es el de Marie Danielle Demellas e Yves Saint Geours. ${ }^{41}$ Se trata de un trabajo muy temprano, escrito entre 1983 y 1984, en diálogo con autores como François-Xavier Guerra y Frederick Mauro, y recogiendo los aportes de Jean Meyer y Guy Hermet. Los autores de Jerusalén y Babilonia incursionaron en una explicación novedosa para su contexto, al mostrar que la sociedad secularizada seguía coexistiendo con una visión cristiana del mundo, de amplia difusión en gran parte de la sociedad ecuatoriana. Así mismo, los autores cuestionaban la supuesta bipolaridad estricta que regiría la política decimonónica del país andino, observando críticamente las aparentemente contradictorias alianzas y recomposiciones de los actores políticos del país.

Hasta periodos muy recientes, han subsistido unas miradas prejuiciosas sobre las élites políticas del siglo XIX latinoamericano, bien como los acérrimos defensores de las costumbres o modernizantes dinámicos, bien como figuras ejemplares o bárbaros caudillos, sus figuras siempre aludirían a dos bloques supremamente definidos y completamente irreconciliables: liberales y conservadores. ${ }^{42}$ Poco a poco, ha venido avanzándose en una revisión de esta explicación sobre la política del siglo XIX; desde finales de la década de 1980, con asiento en la tradición de una renovada historia política y cultural, encarnada en parte en la obra de François Xavier Guerra, una "nueva historia política" ha revaluado esa mirada oscura sobre el antes considerado bárbaro siglo XIX. ${ }^{43}$ En ese contexto se ha madurado la propuesta de Elisa Cárdenas, quien ofrece una mirada objetiva sobre los procesos de secularización, una donde ya no hay unos liberales, modernizantes per se, oprimiendo con justicia a los sectores más recalcitrantes y atrasados, sino una sociedad política moderna en la que la disputa por la hegemonía es el escenario para que cada sector político se la juegue por sus hondas convicciones, entendidas ya no como una justificación de la lógica liberal e ilustrada, sino como representaciones sociales y políticas. ${ }^{44}$

\footnotetext{
${ }^{40}$ Para el caso de Colombia: González Poderes enfrentados, Arias El Episcopado, y Cortés La batalla.

${ }^{41}$ Marie Danielle Demélas e Yves Saint-Geours Yves. Jerusalén y Babilonia. Religión y politica en el Ecuador 1780-1880 (Quito: Corporación Editora Nacional-Instituto Francés de Estudios Andinos, 1988).

${ }^{42}$ Elisa Cárdenas, "El fin de una era: Pío IX y el Syllabus", Historia Mexicana 65.2 (2015): 719 y 720.

${ }^{43}$ Los trabajos más recientes en esta corriente, que a la vez revalúan algunos legados: Elías Palti, El tiempo de la política, el siglo XIX reconsiderado (Buenos Aires: Siglo XXI, 2007); Elías Palti, "De la historia de las ideas a la historia de los lenguajes políticos. Las escuelas recientes de análisis conceptual. El panorama latinoamericano", Anales 7 y 8 (2005): 63-81. También María Teresa Calderón y Clement Thibaud, La majestad de los pueblos en la Nueva Granada y Venezuela 1780-1832 (Bogotá: Universidad Externado de Colombia, 2010), e Iván Jaksic y Eduardo Posada, Liberalismo y poder: Latinoamérica en el siglo XIX (Santiago de Chile: Fondo de Cultura Económica, 2011).

${ }^{44}$ Elisa Cárdenas, "Hacia una historia comparada de la secularización en América Latina”, Ensayos sobre
} 
Del análisis de las relaciones entre el Estado y la Iglesia católica, al estudio conceptual...

De hecho, en entradas más recientes, Cárdenas ha mostrado como el concepto católico de historia comienza a dialogar con el concepto secularizado de Historia, que tan detalladamente estudiara Reinhart Koselleck. ${ }^{45}$ La de esta autora es una evidencia de cómo la historia conceptual de lo político ha redimensionado la visión sobre el mundo católico en el siglo XIX latinoamericano, de ser el lastre que lamentaban recurrentemente los liberales de tradición, o el bastión fielmente defendido según los políticos conservadores, la Iglesia católica ha empezado a enfocarse en los prismas de los historiadores latinoamericanos como una institución o un actor productor y reproductor de representaciones sociales, de prácticas culturales asociativas y letradas; en fin, una arista fundamental en el caleidoscopio que, a nivel cultural y político, representa el siglo XIX para las naciones en formación.

Muestra de esto último es el trabajo de Sol Serrano, ${ }^{46}$ centrado en estudiar la relación de la religión con la política moderna. Serrano afirmaba en su momento que empezaba a ser posible estudiar la secularización ya no como progreso o como ruina, sino como un intenso proceso de la "política moderna en la cultura occidental" ${ }^{47}$ Antes, esta historia de la secularización se había construido en clave teleológica y legislativa, ahora aparecía la posibilidad de observar a la Iglesia como un actor con expectativas y problemáticas, así como los proyectos modernos con sus componentes ambiguos y contradictorios. En fin, la propuesta de Serrano buscaba mostrar la importancia central de los conflictos derivados de la secularización del Estado en América Latina, así como demostrar que "la construcción de la soberanía política moderna en una sociedad proveniente de la unanimidad católica significó una redefinición del concepto de lo público y de su frontera con lo privado". ${ }^{48}$ Todo ello reconociendo que se partía de un caso puntual. Encontramos en este trabajo, entonces, una hoja de ruta historiográfica fascinante, tanto en su propuesta teórica y metodológica -que retomaremos más adelante- como en su potencial heurístico; una investigación que muestra unos ricos insumos documentales, y al mismo tiempo es capaz de conversar con toda una generación de estudiosos latinoamericanos y europeos.

En Argentina también se cuenta con un conjunto de destacados autores que han pensado en la Iglesia católica y su problemática dimensión política, durante el siglo XIX y buena parte del XX. ${ }^{49}$ Miranda Lida y Diego Mauro, por ejemplo, han realizado varias investigaciones sobre el mundo católico argentino del período de mediados de siglo XX, en la década de 1930, así como durante el primer peronismo. ${ }^{50}$ Estos autores

la nueva historia política de América Latina, siglo XIX, ed. Guillermo Palacios (México: El colegio de México, 2007) 197-211.

${ }^{45}$ Cárdenas "El fin" 732.

${ }^{46}$ Sol Serrano, ¿Qué hacer con Dios en la República. Política y secularización en Chile (1845-1885) (Santiago de Chile: Fondo de Cultura Económica, 2008).

${ }^{47}$ Serrano 17 y 18.

${ }^{48}$ Serrano 22.

${ }^{49}$ Fortunato Mallimaci y Roberto DiStefano, Religión e imaginario social (Buenos Aires: Manantial, 2001); Roberto DiStefano, El púlpito y la plaza. Clero, sociedad y política de la monarquía católica a la república rosista (Buenos Aires: Siglo XXI, 2004).

${ }^{50}$ Miranda Lida y Diego Mauro, Catolicismo y sociedad de masas en Argentina, 1900-1950 (Buenos Aires: Prohistoria, 2009). 
subrayan que la consolidación de estudios complejos sobre lo católico desligados de la pertenencia a la institución eclesiástica es un proceso reciente, y al mismo tiempo reconocen que el pluralismo de los enfoques y aproximaciones actuales sería una de las virtudes en esta área de estudio dentro de la historiografía argentina. Mauro, específicamente, ha centrado varios trabajos en la relación entre la sociedad de masas y el lugar que en tal proceso tomó el clero católico. ${ }^{51}$ De manera adyacente, puede observarse que la historia intelectual no ha sido reacia a abordar las transformaciones del mundo católico argentino, especialmente por la riqueza de la producción cultural de los intelectuales católicos durante casi todo el siglo XX. ${ }^{52}$

Este pequeño listado de autores, por supuesto, es apenas una pequeña aproximación a los numerosos trabajos que, solo en la última década, son muy numerosos. ${ }^{53} \mathrm{Si}$ bien es cierto que nuevas lecturas nos darán más luces en torno a las maneras de indagar sobre el mundo católico latinoamericano, con lo brevemente reseñado hasta acá podemos hacernos una idea de al menos dos puntos de partida fundamentales para nuestra propuesta. En primer lugar, pensando específicamente en el siglo XIX, es de una precisión metodológica indiscutible el llamado de atención sobre como la Iglesia y la sociedad civil en clave de política moderna no son dos sectores antagónicos, lo que a su vez deja ver que los procesos de secularización son fenómenos complejos y que no apuntan a la simple eliminación -imposible por demás en sociedades con más de cuatro siglos de tradición católica de cuño hispano- de la influencia cristiana. ${ }^{54}$ La segunda precisión obedece a la riqueza que durante la primera mitad del siglo XX se puede observar en el mundo católico latinoamericano: publicaciones periódicas, sociabilidades, eventos masivos, concursos. En fin, se trata de un componente fundamental de las transformaciones culturales y políticas del siglo pasado.

\section{Dios y la República. Hacia una historia conceptual de las discusiones sobre el catolicismo en Colombia en los siglos XIX y XX}

Nuestra propuesta, como ya se dijo, no es una historia interna de la Iglesia católica colombiana y sus particularidades, ni un tratamiento exclusivo de las relaciones Iglesia-Estado, al contrario, busca considerar como una matriz conceptual el problema

\footnotetext{
${ }^{51}$ Diego Mauro, "Multitudes y movilizaciones católicas en la Argentina de Entreguerras. Cuestiones metodológicas e historiográficas", PolHis. Boletín Bibliográfico del programa Buenos Aires de Historia Politica 4.8 (2012): 90-96; Diego Mauro, "Multitudes católicas, sociedad de masas y política en la Argentina. Reflexiones a partir del Congreso Eucarístico Nacional de 1940", Secuencia 97 (2017): 200-231.

52 José Zanca, "La fe de Prometeo. Crítica y secularización en el catolicismo argentino de los años 50", Prismas. Revista de Historia Intelectual 14 (2010): 95-114; Olga Echeverría, Las voces del miedo. Los intelectuales autoritarios argentinos en las primeras décadas del siglo XX (Rosario: Prohistoria, 2009).

${ }^{53}$ Llama la atención que sea el cono sur uno de los polos de estos avances; tanto en Argentina como en Chile, se han abierto numerosas preguntas sobre la historia del siglo XX, y se ha analizado la influencia de la Iglesia católica durante las dictaduras. Ver los trabajos de Miranda Lida y Jessica Blanco.

${ }^{54}$ De hecho llama la atención como a finales de siglo XX, cuando tal vez se esperaba un desgaste definitivo de la influencia católica, se ha sucedido una explosión de nuevas religiosidades cristianas protestantes, véase: Jean Pierre Bastian, La modernidad religiosa: Europa y América Latina en perspectiva comparada (México: Fondo de Cultura Económica, 2004).
} 
de la secularización en un país latinoamericano. Partiendo de la perspectiva de los lenguajes políticos y de la historia conceptual, se considera que la tarea urgente consiste en reconstruir los componentes intelectuales, los suelos argumentativos donde tomaron forma las representaciones producidas y puestas en circulación en torno a la presencia y transformación de la Iglesia católica. El acumulado de investigaciones para el caso puntual colombiano, antes reseñadas, así como las nuevas perspectivas de otros lugares de América Latina, nos permitirán, por ahora, establecer un primer itinerario temático y documental, así como una ruta metodológica. Se escapa a esta labor, por razones de tiempo y espacio, una inmersión en la historiografía colonial latinoamericana y colombiana, el último caso, por ejemplo, se ha enriquecido recientemente, en tal manera que las miradas han complejizado las investigaciones y enriquecido la comprensión de la Iglesia católica.

El primer elemento por señalar, teniendo en cuenta lo que consideramos como uno de los puntos de partida según la historiografía latinoamericana reciente sobre el catolicismo, es que, antes que una confrontación entre dos bandos, y su respectivo desenlace, fatal o feliz, lo que encontramos es un proceso de múltiples aristas en el que las sociedades católicas abordan los acelerados cambios que la publicidad moderna imponía en el avance del siglo XIX. Si nos ubicamos en la actual Colombia, valdría la pena hacer otra precisión. Dado que siempre los historiadores han tenido presente la enorme influencia del cristianismo en nuestra sociedad, parece aflorar cierta idea engañosa de que, aún durante los casi tres siglos de dominio del catolicismo monárquico hispánico, la Iglesia contó siempre con una perfecta capacidad de hegemonía. Nada más lejos de la realidad; esa mirada, que contribuye a ver a la Iglesia como un bloque más o menos inmóvil, desconoce el problemático proceso de consolidación de la cultura católica durante el período de conquista y durante el siglo XVIII. Ceballos Gómez ha realizado una afirmación que consideramos pionera y hasta ahora desatendida por investigaciones posteriores: "No se puede pensar en la Iglesia como formadora de una cultura religiosa en la época colonial. Solo en el siglo XIX emprende la Iglesia la tarea de la reeducación religiosa; si con los Borbones se dio la recapturación de América, con la Iglesia en el siglo XIX se dio la reconquista espiritual, reconquista que se perfilaba desde el siglo XVIII". ${ }^{55}$

El siglo XIX es un momento de recomposición y ofensiva de la Iglesia católica, en términos generales, en las nacientes repúblicas hispanoamericanas, y de modo particular, en la República neogranadina y colombiana. Antes del tramo decimonónico, no se podía decir que todos eran sumisos y fieles cristianos. Esto se podría ver de un modo más claro cuando se exploran experiencias del siglo XVIII; Abadía, por ejemplo, ha mostrado como en la primera mitad de este siglo el Cabildo de Santiago de Cali incrementó sus llamados al orden, así como la existencia de comerciantes, indígenas y libres de todos los colores, bastante reacios a detener sus actividades cotidianas para brindarle su tiempo al culto católico. ${ }^{56}$ No conocemos la historiografía

\footnotetext{
${ }^{55}$ Ceballos Gómez 99.

${ }^{56}$ Carolina Abadía, De cómo salvar el alma. Estudio de la religiosidad popular, devocional y testamental de Santiago de Cali (1700-1750) (Cali: Universidad del Valle, 2014) 61-76.
} 
colonial sobre lo religioso con una profundidad suficiente, pero nos interesa señalar estas apreciaciones, especialmente la de Ceballos Gómez, para entender con mayor exactitud las transformaciones decimonónicas, tales como el despliegue asociativo católico que han analizado autores como Gilberto Loaiza. En fin, el siglo XIX antes que ser la simple continuidad del catolicismo monárquico español, es el momento inaugural de una Iglesia católica en movimiento, deslindada del regalismo y con el interés en fortalecer sus relaciones con Roma.

Esta última afirmación, creemos, nos indica la necesidad de una mirada hermenéutica; debemos cuestionar una cierta mirada teleológica, y casi inconsciente, que plantearía que el origen del catolicismo integralista se remonta al casi inmemorial siglo XVI, y que se ha mantenido casi igual hasta el presente; varias investigaciones en el ámbito nacional dan cuenta de que incluso durante el "Antiguo Régimen" esa realidad monolítica no puede postularse. Una cosa es subrayar la debilidad de los postulados laicos y los proyectos secularizadores de la tradición liberal colombiana, y otra muy diferente es proponer que la Iglesia ha mantenido su lugar hegemónico siempre inalterado, y que éste le ha costado los mismos esfuerzos durante los siglos XIX y $\mathrm{XX}$, que por demás serían mínimos. Acá nos parece importante regresar al trabajo de Sol Serrano, quien rescató la figura de Rafael Valentín Valdivieso, arzobispo de la diócesis de Santiago en un tiempo de debates y conflictos:

La principal dificultad de la Iglesia en el siglo no fue, a pesar de todo, el conflicto político. La principal dificultad era la geografía, un territorio gigantesco cortado por accidentes naturales que determinaban las comunicaciones humanas y una población escasamente congregada. La geografía humana, una herencia antigua, era imposible de vencer en una sociedad agraria preindustrial que recién descubría el mercado y que no conocía y parecía no necesitar la tecnología. ${ }^{57}$

La Iglesia católica chilena, en cabeza del personaje antes mencionado, tuvo la difícil tarea de organizar archivos parroquiales y formar al clero que tenía un contacto más constante con la población; en ese proceso llama la atención el desplazamiento que hace la institucionalidad católica desde las concepciones de un derecho particular, típico de una sociedad estamental monárquica, hacia las de un derecho general, ${ }^{58} \mathrm{en}$ sintonía con la consolidación de un régimen político democrático: organizar padrones, rescatar archivos, uniformar la doctrina, sintonizarse con la institución papal, entre otras.

Los temas analizados por Serrano, además de la interesante figura de un arzobispo en la década de 1860, son la caridad católica y la asistencia social brindada por la Iglesia católica; el lugar de las cofradías en la vida cultural y política; el desgaste del dominio católico sobre los cementerios; la Iglesia católica en el contexto urbano y rural, entre otros. Sin embargo, una de las líneas que atraviesa su trabajo es el proceso de adecuación de la Iglesia a las tácticas y estrategias de la opinión pública:

\footnotetext{
${ }^{57}$ Serrano 50.

${ }^{58}$ Serrano 70.
} 
El desenlace había sido finalmente una negociación en la esfera moderna dentro de cuya lógica participaba el catolicismo, aunque no la aceptara doctrinariamente. La secularización del Estado se había realizado en contra de la Iglesia, pero el catolicismo había construido estas nuevas prácticas políticas y sociales para reacomodar su espacio [...] La privatización del catolicismo era también su publicidad moderna. ${ }^{59}$

Una de las tipologías documentales trabajada por esta autora, a parte de los periódicos católicos, son los documentos de las visitas arzobispales, así como la correspondencia de algunos miembros del clero.

Ahora bien, temáticamente hablando, es este último punto el que queremos tener como centro en el análisis a realizar de los conceptos y los lenguajes políticos. La Iglesia católica, antes que una institución cerrada al cambio, mostró su amplísimo potencial para recibir y transformar -resemantizar- las prácticas y los códigos culturales que implicaba la adopción de un régimen político democrático. El ultramontanismo, o el catolicismo integral o "intolerante", no cerró filas en torno a sus viejas prácticas; al contrario, durante la primera parte del siglo XIX buscó afirmar su autonomía del poder civil, y durante la segunda desplegó sociedades, impresos y rituales públicos, que fortalecieron su lugar dentro de las transformaciones. Se trata de una larga serie de transformaciones, en ninguna medida simples, que inicia - para efectos de una periodización inicial, y centrados en el caso colombiano- con el lugar preponderante de la figura de Dios y la religión en la Constitución de 1886, producto, esta última, de Miguel Antonio Caro, un reconocido publicista e intelectual católico. Y que termina en los años sesenta del siglo XX, con la aparición de nuevas corrientes intelectuales, en sintonía con debates internacionales, así como en los momentos previos al concilio Vaticano II. ${ }^{60}$

Este largo período, entre la última década del siglo XIX, y toda la mitad del XX, estuvo atravesado por múltiples discusiones, asumidas tanto por las autoridades católicas, como por los intelectuales conservadores y liberales. ${ }^{61}$ Estas ofrecen matices particulares en los congresos eucarísticos colombianos de 1913 (Bogotá), 1935 (Medellín) y 1949 (Cali). ${ }^{62}$ Se trata de rupturas que recogen momentos trascendentales para el mundo cultural y político de aquellos años; la experiencia del republicanismo (1910-1914); la llamada República Liberal (1930-1945), y la Restauración Conservadora (19461957). Estos elementos serían indicadores de la maleabilidad de la institucionalidad

\footnotetext{
${ }^{59}$ Serrano 343.

${ }^{60}$ De modo tentativo podría pensarse en llevar esta delimitación temporal hasta 1962, sin que ello altere en demasía el fenómeno que se busca comprender.

${ }^{61}$ En el período de la Regeneración, como lo señala Óscar Blanco, hubo un componente fuertemente católico, aunque no puede sustentarse que haya permanecido intacto durante todo el siglo XX: Óscar Blanco, "La nación católica durante la Regeneración (1886-1900): perspectivas historiográficas", Anuario de Historia Regional y de las Fronteras 13.1 (2008): 172.

${ }^{62}$ Sobre los dos primeros no tenemos ningún registro historiográfico, sobre el último hemos dedicado algunas líneas, en la perspectiva que vincula el mundo católico a la masificación política de la década de 1940, ver Joan Manuel Largo, "Imaginarios y representaciones sobre el pueblo. Cali, 1945-1950" (Tesis, pregrado en Historia, Universidad del Valle, 2013) 154-176.
} 
católica y sus representantes, así como su efectividad a la hora de influir en las decisiones políticas. Antes, en el siglo XIX, encontramos las visitas arzobispales y la producción de impresos como dos prácticas importantes y susceptibles de un seguimiento detallado. Las afirmaciones de los intelectuales del período estudiado, dispersas en correspondencia y archivos personales, pueden permitir un acercamiento a los lenguajes políticos de lo religioso y lo católico en la primera mitad del siglo XX. Y este es justamente el registro documental que podría aportar más luces dentro del análisis conceptual y lingüístico de la secularización.

En ejercicios documentales anteriores hemos podido rastrear la importancia de las autoridades eclesiásticas en la vida de los Concejos Municipales, específicamente en el caso de Medellín; los días del Corpus Cristhi, por ejemplo, representaban en Medellín un despliegue de desfiles, invitaciones, impresos y eucaristías. Las fiestas de independencia, en Cali, incluyeron siempre una eucaristía pública. Además de los archivos de los concejos, creemos, la revisión de libros publicados por intelectuales del período, así como de algunos archivos personales, dejan entrever que el lugar de la Iglesia era un tema insoslayable para pensar y discutir el arte, la política, la literatura y hasta la vida cotidiana. Finalmente, resultan de gran utilidad los archivos eclesiásticos, cuya disponibilidad se ha ampliado en los últimos años, así como los fragmentos que, de los impresos católicos, se han conservado en la Biblioteca Nacional de Colombia, y en la Biblioteca Luis Ángel Arango. Muestra de lo anterior puede observarse en el trabajo más reciente de Cortés, en el que desfila un número considerable de libros, impresos y memorias del siglo XIX. ${ }^{63}$

Una vez acopiado este material, y esbozada una línea temporal que nos permita subrayar unos momentos de ebullición, el siguiente paso es inventariar y reinscribir en el contexto, los textos de los intelectuales y las autoridades católicas, no en una correspondencia simple y directa, sino buscando identificar unas condiciones de posibilidad. Así las cosas, se buscará superar el "qué se dijo", para responder cómo fue posible que se dijera aquello qué se dijo. Planteamos como hipótesis a demostrar que los lenguajes políticos del mundo democrático fueron apropiados en clave católica por la Iglesia y sus defensores; que así, paulatinamente, las referencias bíblicas, las prácticas devocionales, las festividades, fueron aminorando su carga semántica barroca para abrazar sin mucha confianza, pero si con fruición, los elementos de la llamada cultura política "moderna". Ahora los católicos habrían de salir con la pluma y no con lanzas, no se iban a quedar en los templos y en sus casas, iban a luchar con esas "máquinas de guerra" de las sociedades modernas". ${ }^{64}$ Los componentes intelectuales que evocaban los actores de las discusiones, bien sea que éstos acudieran a unos espacios de experiencia comunes, o dibujaran unos utópicos horizontes de expectativa, nos ayudarán así a elaborar varias precisiones sobre los lenguajes políticos del período, así como a afirmar que el de Secularización, fue uno de los conceptos fundamentales en la Colombia finisecular y de la primera mitad del siglo XX.

\footnotetext{
${ }^{63}$ Cortés La batalla.

${ }^{64}$ Serrano 338.
} 
Ahora bien, la apretada síntesis que hemos realizado hasta acá - un brochazo inicial al que se escapan varios trabajos - de ninguna manera ha sido realizada para desautorizar los avances que en materia de la historia de las relaciones entre Iglesia y Estado en Colombia se han realizado recientemente; muy al contrario, lo que se busca es ponderar los hallazgos y avances en esta materia para proponer una perspectiva de análisis compleja, en la que el énfasis sea puesto en el concepto de Secularización a través de la metodología de la historia conceptual y de los lenguajes políticos. Existe una importante discusión contemporánea en las ciencias sociales en torno al tema de la secularización, especialmente desde la filosofía y la sociología. ${ }^{65}$ Casanova señala la diversidad de las experiencias occidentales, así como la multiplicidad de modernidades, enfatizando en la cultura católica y su sello peculiar, dada la colisión entre la religión y las esferas seculares; ${ }^{66}$ mientras que Taylor intenta rastrear y definir el cambio que ha llevado desde unas sociedades en las que era imposible no creer en Dios, hasta otras donde la fe es una posibilidad humana entre otras. ${ }^{67}$ Esta definición desde la vertiente anglosajona no dista mucha de la de Cárdenas Ayala, quien por secularización entiende: "la construcción de una forma de legitimidad del poder fundada en bases puramente humanas". ${ }^{68}$

La larga red de transformaciones semánticas de la noción de secularización se remonta a, por lo menos, unos cuatro siglos; de ahí que Giacomo Marramao haya observado una pertinente vía de análisis desde la historia de conceptos del Geschichtliche Grundbegriffe de Otto Brunner, Werner Conze y Reinhart Koselleck. ${ }^{69}$ Este filósofo italiano recuerda el proceso mediante el cual la dimensión del futuro empieza a reemplazar el horizonte de las escatologías judeocristianas, ${ }^{70}$ señalando además la cuestión de la "futurización" o aceleración de la modernidad, que bien ha retratado Koselleck..$^{71}$ Justamente en estas coordenadas de la historia de conceptos se han realizado aproximaciones a este concepto en el contexto de la España del siglo XX, develando la pluralidad de sentidos y su cercanía con voces como "laicización" o "desacralización", así como su sentido jurídico-político de larga data. ${ }^{72}$ La reconstrucción semántica que logran La Parra y Fernández Sebastián da cuenta de la elasticidad del concepto, así como de las numerosas experiencias de las que se alimentó, desde la intransigencia de un Donoso Cortés hasta las ambivalencias de José Ortega y

\footnotetext{
${ }^{65}$ José Casanova, "Rethinking secularization: a global comparative perspective", The hedgehog Review, Spring \& Summer: 8 (2006): 7-23. Charles Taylor, A secular age (Cambridge: Harvard University Press, 2007).

${ }^{66}$ Casanova 11.

${ }^{67}$ Taylor 3.

${ }^{68}$ Elisa Cárdenas, "La construcción de un orden laico en América hispánica. Ensayo de interpretación sobre el siglo XIX", Los retos de la laicidad y la secularización en el mundo contemporáneo, coord. Roberto Blancarte (México: El Colegio de México, 2008) 85.

${ }^{69}$ Giacomo Marramao, Poder y secularización (Barcelona: Península, 1989) 16 y 23.

${ }^{70}$ Marramao 200.

${ }^{71}$ Reinhart Koselleck, Futuro pasado: para una semántica de los tiempos históricos (Madrid: Paidós, 1993) 31.

${ }^{72}$ Javier Fernández Sebastián y Emilio La Parra López, "Secularización”, Diccionario político y social del siglo XX español, Dir. Javier Fernández Sebastián y Juan Francisco Fuentes (Madrid: Alianza Editorial, 2008) 1081.
} 
Gasset e incluso pasando por la experiencia del Concilio Vaticano II. En suma, antes que un sentido definitivo del concepto de secularización pretendemos reconstruir la densidad semántica de este en las coordenadas particulares de la Colombia de finales del siglo XIX y primera mitad del siglo XX, desde un enfoque no teleológico que asuma como premisa que no hay un sentido único que el historiador pueda develar como verdad definitiva, sino que justamente lo aporético e irresoluble, ${ }^{73}$ debe ser analizado desde sus circunstancias de emergencia para lograr una mejor comprensión de las transformaciones y continuidades.

\section{Conclusión}

Los trabajos de historia de la Iglesia católica no pueden girar en torno a una descripción autocontenida del fenómeno religioso, como si este fuera un hecho que encontrara su única lógica posible en su propio interior, desprovisto del sentido que confieren otras dinámicas sociales. ${ }^{74}$ La historiografía colombiana sobre las relaciones Iglesia-Estado previamente revisada ha tenido enormes avances: los estudios en perspectiva regional, las publicaciones colectivas, la cercanía con el enfoque francés y anglosajón, entre otros. Estos son los insumos necesarios para que, en diálogo con la historiografía latinoamericana reciente de la Iglesia católica, se pueda avanzar hacia un análisis conceptual y lingüístico de la Secularización. Así las cosas, ha dejado de ser necesario profundizar en reflexiones filosóficas, que otorgan una alteridad hipersensible y extrema al hecho de la creencia y la fe, velando cada vez más su sustento intelectual, en lugar de aportar claridad sobre sus maneras de articulación. Por el contrario, lo que debe buscarse, teniendo en cuenta los aportes de la bibliografía local y las experiencias investigativas latinoamericanas, es la consideración de los contextos argumentativos que dieron lugar a unos debates precisos. La reconstrucción de las racionalidades que priman en los lenguajes políticos se presenta como una valiosa oportunidad para retomar aportes clásicos de las historiografías locales, poniendo en diálogo estos avances con interpretaciones más generales. Desde una mirada un tanto esquemática, que por vía de una excesiva atención a los códigos legislativos y a los acontecimientos superficiales, puede avanzarse, así, hacia un análisis de los componentes lingüísticos y conceptuales del fenómeno de la Secularización, que comprende ya no un dúo irreconciliable en términos maniqueos, sino que da cuenta de una faceta de connotaciones universales, de la irrupción e intensificación de la contingencia en el mundo de lo político.

Además, cuando se habla de secularización se tiende a entender de una manera más universal y compleja los procesos de cambio que ha enfrentado, de manera puntual, la institucionalidad católica. No se trata ya de una estructura que se reúse al cambio, al contrario, poniendo en evidencia su característica maleabilidad humana se adaptó

\footnotetext{
${ }^{73}$ Reinhart Koselleck, Esbozos teóricos ¿Sigue teniendo utilidad la historia? (Madrid: Escolar y Mayo, 2013) 38 .

74 “Toda la historia permanece insensata. Razonable es como mucho su análisis. [...] Necesitamos incluso la narración para ilustrar lo aporético, para hacerlo en cualquier caso perceptible, aunque no pueda entenderse ni comprenderse racionalmente": Koselleck, Esbozos 38.
} 
con rapidez a los ritmos y a las racionalidades que se iban imponiendo. Así, hablar de secularización no es plantear entonces una línea de desgaste definitivo de las lógicas de la racionalidad católica, se trata más bien de apuntalar un espacio temporal en el que se configuran y hacen eclosión unos nudos de problemas; el centro del estudio, entonces, ya no pueden ser los contenidos puntuales del arsenal de intervenciones de las instituciones eclesiásticas, sino más bien las maneras en las que dichos contenidos pudieron organizarse para crear un sentido en la discusiones públicas. Más allá de las ideas católicas, debe llegarse entonces al análisis de los lenguajes políticos, así como de aquellas nociones que en los siglos XIX y XX fungieron como conceptos capaces de condensar espacios de experiencia y horizontes de expectativa.

Carl Schmitt, el jurista alemán, habló de Secularización en los conceptos de su teología política, así como en su tratamiento del romanticismo político, y fue tal vez por esa vía que el profesor colombiano Rafael Gutiérrez Girardot hizo un uso esclarecedor del mismo en su tratamiento del modernismo literario en América Latina, así como para el estudio de ciertas transformaciones en la escena literaria colombiana e hispanoamericana. ${ }^{75}$ Martin Heidegger habló de la "desdivinización", según una problemática y tardía traducción al castellano, ${ }^{76}$ mientras que Max Weber insistió en el desencantamiento del mundo, con una fuerte inclinación por los fenómenos religiosos. ${ }^{77}$ Alberto Mayor Mora, receptor de Weber -a quien falta criticar con voces como las de Peter Laslett o Marcel Gauchet en aras de una visión un poco más depurada de esta influencia de lo religioso- se ha acercado al tratamiento de las lógicas religiosas con relación a los fenómenos económicos, pero es aún grande el trayecto que resta por recorrer. ${ }^{78}$ Hasta acá resulta apenas posible dibujar un camino novedoso en el tratamiento de lo religioso-católico, específicamente para el caso particular colombiano, y proponiendo como un espacio temporal pertinente las últimas dos décadas del siglo XIX y la primera mitad del XX, no tanto por lo reciente de los aportes, sino por el margen de posibilidades metodológicas y documentales que abre la comprensión conceptual y lingüística de la Secularización, al estudioso interesado en poder dialogar con experiencias latinoamericanas y europeas sin perder de vista la especificidad de su caso singular.

\footnotetext{
${ }^{75}$ El sacerdocio privado o sacerdocio de sí mismo, será la fórmula que utilice para hablar de lo que consideraba la expresión intelectual de la emergente burguesía: Carl Scmitt, Romanticismo político (Buenos Aires: Universidad Nacional de Quilmes, 2000) 59-61.

76 "Desdivinización es el doble proceso de cristianizar la imagen del mundo, al colocar por una parte como fundamento del mundo lo infinito, lo incondicionado, lo absoluto y, por otra, transformando el cristianismo, su cristianismo en una visión del mundo (la visión cristiana del mundo) y al hacerla moderna de esta suerte": Martin Heidegger, Sendas perdidas (Buenos Aires: Losada, 1979) 68.

${ }^{77}$ Marramao 26.

${ }^{78}$ Alberto Mayor Mora, Ética, trabajo y productividad en Antioquia (Bogotá: Tercer Mundo, 1994).
} 


\section{Bibliografía}

\section{Fuentes secundarias}

\section{Libros}

Abadía, Carolina. De cómo salvar el alma. Estudio de la religiosidad popular, devocional y testamental de Santiago de Cali (1700-1750). Cali: Universidad del Valle, 2014.

Abel, Christopher. Política, Iglesia y Partidos en Colombia: 1886-1953. Bogotá: Faes-Universidad Nacional de Colombia, 1987.

Arango, Gloria Mercedes. Sociabilidades católicas, de la tradición a la modernidad, Antioquia 1870-1930. Medellín: La carreta, 2004.

Arias, Ricardo. El episcopado colombiano. Intransigencia y laicidad 1850-2000. Bogotá: Universidad de los Andes-Icanh, 2003.

Bastian, Jean Pierre (Dir.). La modernidad religiosa: Europa y América Latina en perspectiva comparada. México: Fondo de Cultura Económica, 2004.

Bastian, Jean-Pierre. Protestantismos y modernidad en América Latina. Historia de unas minorías religiosas activas en América Latina. México: Fondo de Cultura Económica, 1994.

Bautista, Cecilia. Las disyuntivas del Estado y de Iglesia en la consolidación del Orden Liberal. México, 1856-1910. México: El Colegio de México, 2012.

Beltrán, William. Del monopolio católico a la explosión pentecostal. Pluralización religiosa, secularización y cambio social en Colombia. Bogotá: Universidad Nacional de Colombia, 2013.

Bidegain, Ana María. Historia del Cristianismo en Colombia. Corrientes y diversidad. Bogotá: Taurus, 2004.

Bidegaín, Ana María y Demera, Juan Diego. Globalización y diversidad religiosa en Colombia. Bogotá: Universidad Nacional de Colombia, 2005.

Bidegaín, Ana María. Iglesia, pueblo y política. Un estudio de conflictos de intereses: Colombia, 1930-1955. Bogotá: Universidad Javeriana, 1985. 
Del análisis de las relaciones entre el Estado y la Iglesia católica, al estudio conceptual...

Caicedo Amanda. Construyendo la hegemonía religiosa. Los curas como agentes hegemónicos y mediadores socioculturales (Diócesis de Popayán, Siglo XVIII). Bogotá: Universidad de los Andes, 2008.

Castro, Beatriz. La relación entre la Iglesia católica y el Estado Colombiano en la Asistencia social c. 1870-1960. Cali: Universidad del Valle, 2014.

Ceballos Gómez, Diana Luz. Hechicería, brujería e inquisición en el Nuevo Reino de Granada. Un duelo de Imaginarios. Bogotá: Universidad Nacional de Colombia, 1994.

Cortés José David. Curas y políticos: mentalidad religiosa e intransigencia en la diócesis de Tunja, 1881-1918. Bogotá: Ministerio de Cultura, 1998.

Cortés, José David. La batalla de los siglos. Estado, Iglesia y religión en Colombia en el siglo XIX. De la Independencia a la Regeneración. Bogotá: Universidad Nacional de Colombia, 2016.

Demélas, Marie Danielle y Saint-Geours Yves. Jerusalén y Babilonia. Religión y politica en el Ecuador 1780-1880. Quito: Corporación Editora Nacional-Instituto Francés de Estudios Andinos, 1988.

DiStefano, Roberto. El púlpito y la plaza. Clero, sociedad y política de la monarquía católica a la república rosista. Buenos Aires: Siglo XXI, 2004.

Dosse, Francois. La historia en migajas: de Annalesa la "nueva historia”. México: Universidad Iberoamericana, 2006.

Echeverría, Olga. Las voces del miedo. Los intelectuales autoritarios argentinos en las primeras décadas del siglo XX. Rosario: Prohistoria, 2009.

Echeverry, Antonio y Abadía, Carolina. Aproximación histórica a la Diócesis de Cali. Cali: Universidad del Valle, 2010.

Echeverry, Antonio y Abadía, Carolina. Historia de la Iglesia Católica en el Valle del Cauca. Cali: Universidad del Valle, 2015.

Foucault, Michel. La arqueología del saber. México: Siglo XXI, 2001.

García, Pilar. Iglesia y poder en el Perú contemporáneo, 1821-1919. Lima: Centro de Estudios Regionales Andinos, 1991.

González, Fernán. Para leer la política. Ensayos de historia colombiana. 2 tomos. Bogotá: Cinep, 1997. 
González, Fernán. Poderes enfrentados. Iglesia y Estado en Colombia. Bogotá: Cinep, 1997.

Grupo de investigación Religión, Cultura y Sociedad, Historiografía sobre religión, cultura y sociedad en Colombia producida entre 1995 y el 2000. Cuaderno de trabajo No. 1. Medellín: Todográficas, 2001.

Heidegger, Martin. Sendas perdidas. Buenos Aires: Losada, 1979.

Jaksic, Iván y Posada, Eduardo. Liberalismo y poder: Latinoamérica en el siglo XIX. Santiago de Chile: Fondo de Cultura Económica, 2011.

Koselleck, Reinhart. Futuro pasado: para una semántica de los tiempos históricos. Madrid: Paidós, 1993.

Koselleck, Reinhart. Esbozos teóricos ¿Sigue teniendo utilidad la historia? Madrid: Escolar y Mayo, 2013.

Larosa, Michael. De la derecha a la izquierda. La Iglesia católica contemporánea. Bogotá: Planeta, 2000.

Lida, Miranda y Mauro, Diego. Catolicismo y sociedad de masas en Argentina, 19001950. Buenos Aires: Prohistoria, 2009.

Loaiza, Gilberto. Poder letrado. Ensayos sobre historia intelectual de Colombia, Siglos XIX y XX. Cali: Universidad del Valle, 2014.

Loaiza, Gilberto. Sociabilidad, religión y politica en la definición de la Nación. Colombia 1820-1886. Bogotá: Universidad Externado de Colombia, 2011.

Londoño, Patricia. Religión, cultura y sociedad en Colombia. Medellín y Antioquia, 1850-1930. Bogotá: Fondo de Cultura Económica, 2004.

Mallimaci, Fortunato y DiStefano Roberto (comp.). Religión e imaginario social. Buenos Aires: Manantial, 2001.

Marramao, Giacomo. Poder y secularización. Barcelona: Península, 1989.

Ortiz, Luis Javier y otros. Ganarse el cielo defendiendo la religión. Guerras civiles en Colombia, 1840-1902. Medellín: Universidad Nacional de Colombia, 2005.

Ortiz, Luis Javier. Fusiles y plegarias. Guerra de guerrillas en Cundinamarca, Boyacá y Santander. Medellín: Universidad Nacional de Colombia, 2004.

Ortiz, Luis Javier. Obispos, clérigos y fieles en pie de guerra. Antioquia 1870-1880. Medellín: Universidad Nacional de Colombia, 2010. 
Del análisis de las relaciones entre el Estado y la Iglesia católica, al estudio conceptual...

Palacios, Guillermo. Ensayos sobre la nueva historia política de América Latina, siglo XIX. México: El Colegio de México, 2007.

Palti, Elías. El tiempo de la política, el siglo XIX reconsiderado. Buenos Aires: Siglo XXI, 2007.

Plata, William. El hecho religioso: historia en perspectiva regional. Bucaramanga: Universidad Industrial de Santander, 2013.

Scmitt, Carl. Romanticismo político. Buenos Aires: Universidad Nacional de Quilmes, 2000 .

Serrano, Sol. ¿Qué hacer con Dios en la República. Política y secularización en Chile (1845-1885). Santiago de Chile: Fondo de Cultura Económica, 2008.

Silva Renán. Lugar de dudas. Sobre la práctica del análisis histórico: breviario de inseguridades. Bogotá: Universidad de los Andes, 2014.

Taylor, Charles. A secular age. Cambridge: Harvard University Press, 2007.

\section{Capítulos de libro}

Arias, Ricardo. "La historiografía de la Iglesia católica en Colombia", en Maya, Adriana y Bonnet, Diana. Balance y desafio de la Historia de Colombia al inicio del siglo XXI. Homenaje a Jaime Jaramillo Uribe. Bogotá: Universidad de los Andes, 2003.

Aurell, Jaume. "La transición de los setentas: de las economías a las mentalidades". La escritura de la memoria: de los positivismos a los posmodernismos. Valencia: Universitat de Valencia, 2005.

Cárdenas, Elisa. "La construcción de un orden laico en América hispánica. Ensayo de interpretación sobre el siglo XIX". Los retos de la laicidad y la secularización en el mundo contemporáneo. Coord. Roberto Blancarte. México: El Colegio de México, 2008.

Carmagnani, Marcello. “Campos, Prácticas y Adquisiciones de la historia política latinoamericana”. Ensayos sobre la nueva historia política de América Latina, siglo XIX. Ed. Guillermo Palacios. México: El Colegio de México, 2007.

Fernández Sebastián, Javier y Emilio La Parra López. "Secularización”. Diccionario político y social del siglo XX español. Dir. Javier Fernández Sebastián y Juan Francisco Fuentes. Madrid: Alianza Editorial, 2008. 
Loaiza, Gilberto. "La utopía conservadora de la nación católica", Utopías Móviles. Nuevos caminos para la historia intelectual en América Latina. Ed. Selnich Vivas. Bogotá: Diente de León-Universidad de Antioquia, 2014.

Malamud, Carlos. “¿Cuán nueva es la nueva historia política latinoamericana?”. Ensayos sobre la nueva historia política de América Latina, siglo XIX. México: El Colegio de México, 2007.

Tenorio, Mauricio. "Historia, cultura y 'América Latina'. Las dos últimas décadas del siglo XX”, Historia General de América Latina, Volumen IX, Teoría y Metodología de la Historia de América Latina. París: Ediciones Unesco-Editorial Trotta, 2006.

\section{Artículos de revista}

Arce, Viviana. "El púlpito entre el temor y la esperanza: ideas de castigo divino y misericordia de Dios en la oratoria sagrada neogranadina, 1808-1820". Anuario de Historia Regional y de las Fronteras 17.1 (2012): 77-107.

Arce, Viviana. "La Biblia como fuente de reflexión política en los sermones neogranadinos, 1808-1821”. Revista CS 9 (2012): 273-307.

Blanco, Óscar. "La nación católica durante la Regeneración (1886-1900): perspectivas historiográficas". Anuario de Historia Regional y de las Fronteras 13. 1 (2008): 157180.

Cárdenas, Elisa. "El fin de una era: Pío IX y el Syllabus". Historia Mexicana 65.2 (2015): 719-746.

Casanova, José. "Rethinking secularization: a global comparative perspective". The hedgehog Review Spring \& Summer.8 (2006): 7-23.

Cortés, José David. "Balance bibliográfico sobre la historia de la Iglesia católica en Colombia, 1945-1995”. Historia Crítica 12 (1996): 17-27.

Cortés, José David. "Balance historiográfico sobre las relaciones Estado-Iglesia en Colombia desde la Independencia hasta finales del siglo XIX". Historia y sociedad 18 (2010): 163-170.

Cortés, José David. "La lealtad al monarca español en el discurso político religioso en el Nuevo Reino de Granada". Anuario Colombiano de Historia Social y de la Culturan 37.1 (2010): 43-83.

De la Ossa, Iván Alexander. "Santificados sean los próceres: historia y religiosidad en los centenarios payaneses, 1910-1916”. Historia y Espacio 45 (2015): 119-145. 
Del análisis de las relaciones entre el Estado y la Iglesia católica, al estudio conceptual...

Largo, Joan Manuel. "Los espacios para la acción. Intersticios y tramas en la construcción del relato en la Microhistoria y el Marxismo Británico". Anuario de Historia Regional y de las Fronteras 22.2 (2017): 143-163.

Mauro, Diego. "Multitudes católicas, sociedad de masas y política en la Argentina. Reflexiones a partir del Congreso Eucarístico Nacional de 1940”. Secuencia 97 (2017): 200-231.

Mauro, Diego. "Multitudes y movilizaciones católicas en la Argentina de Entreguerras. Cuestiones metodológicas e historiográficas". PolHis. Boletín Bibliográfico del programa Buenos Aires de Historia Política 4.8 (2012): 90-96.

Muñoz, Fernando. “Aproximación al imaginario religioso del periodo independentista". Historia y Espacio 35 (2010): 177-200.

Ortiz, Luis Javier. "Manuel Canuto Restrepo y Villegas, 1825-1891. Un obispo en guerras civiles colombianas, entre la Comuna de París y la Comuna de Pasto". Historia y Espacio 37 (2011): 147-187.

Palti, Elías. "De la historia de las ideas a la historia de los lenguajes políticos. Las escuelas recientes de análisis conceptual. El panorama latinoamericano". Anales 7 y 8 (2005): 63-81.

Rueda, José. "Balance historiográfico de una nación fragmentada y en conflicto, 1999-2009”. Boletín Cultural y Bibliográfico 45.79-80 (2011): 193-252.

Santos, Adriana. "Civilización e instrucción pública en los territorios nacionales: consensos entre liberales radicales e Iglesia católica del Magdalena". Historia Caribe 7.21 (2012): 27-53.

Santos, Adriana. "Conectarse con Dios en la frontera. Impresos católicos y sociedad: la experiencia del Magdalena durante los gobiernos liberales radicales del siglo XIX". Historia y Espacio 37 (2011): 127-146.

Zanca, José. "La fe de Prometeo. Crítica y secularización en el catolicismo argentino de los años 50". Prismas. Revista de Historia Intelectual 14 (2010): 95-116.

\section{Tesis, ponencias, documentos y otros Inéditos}

Largo, Joan Manuel. "Imaginarios y representaciones sobre el pueblo. Cali, 19451950”. Tesis inédita de pregrado en Historia, Universidad del Valle, 2013.

Santos, Adriana. “¡Ni tan lejos ni tan cerca!: construcción de la Iglesia en tiempos del liberalismo. La experiencia del magdalena en el Caribe colombiano (1850-1880)". Tesis inédita de Doctorado en Historia, Universidad Pablo de Olavide, 2015. 